\title{
FORMALISMO Y ANTIFORMALISMO EN EL IMPERIO DE LA LEY DE F. LAPORTA
}

\author{
Jesús Vega \\ Universidad de Alicante
}

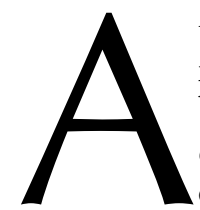

unque El imperio de la ley persigue refundar o, como dice su autor, «reinventar» las ideas fundamentales del legalismo clásico, pretende sin embargo hacerlo evitando reproducir los mismos errores — no menos clásicos- del formalismo jurídico protopositivista. Es interesante discutir si este intento puede juzgarse exitoso o más bien problemático. A lo largo del libro se detecta una tensión permanente e irresuelta entre una tendencia formalista de base en la reconstrucción que LAPORTA emprende del ideal del imperio de la ley y una tendencia antiformalista que trata de superar los déficits que conocidamente acompañan a ese ideal desde el surgimiento mismo del Estado legal de Derecho (e incluso antes de él) y que se harían aún más manifiestos en el Estado constitucional. Esa tensión trae consigo como contrapartida la necesidad para el autor de incorporar importantes dosis de ambigüedad metateórica. Es decir, la tensión solo queda aparentemente resuelta a costa de una constante oscilación en cuanto a la propia adscripción a una posición positivista o a una posición post-positivista en relación con el Derecho, de manera que la frontera entre ambas resulta a menudo traspasada, a lo largo de los diferentes contextos de análisis, de modo inadvertido o implícito.

En la medida en que LAPORTA reivindica los atributos clásicos de la ley - la generalidad y la abstracción- como constitutivos del núcleo central del Derecho y hace residir la esencia del imperio de la ley en «esa clase especial de normas que llamamos en sentido estricto "reglas" [...] no principios, ni estándares, ni valores, ni directivas de otro tipo, sino reglas» $(84,107)^{1}$, tiende a acentuar y abrazar los elementos más fuertemente formalistas del iuspositivismo. Así, el imperio de la ley sería «una reivindicación del papel que las leyes entendidas como vehículo de reglas han de jugar en el ordenamiento jurídico y en la práctica del Derecho» (169). De ahí que el autor se declare sin ambages (y con un evidente punto de provocación) como «formalista» y rechace de plano la carga peyorativa que arrastra esta etiqueta (el «formalismo jurídico»). Enfatiza aquí la función de las leyes-reglas como límites autoritativos de la decisión jurídica, instrumentos que agotarían toda su racionalidad funcionando en términos metodológicos fundamentalmente textualistas y subsuntivos, es decir, como pautas «rígidas» o «mecánicas» al modo positivista o formalista tradicional, un enfoque todavía en buena medida vigente gracias a reactualizaciones del tipo de la de

\footnotetext{
1 Los números indican páginas del libro (LAPORTA, 2007).
} 
SCHAUER (1999) y su teoría de las reglas como «generalizaciones atrincheradas» dotadas de «autonomía semántica», enfoque que LAPORTA acepta de buen grado. Por «formalismo» se entiende entonces la idea de que la justicia formal que emana del imperio de la ley — «entendido como imperio de reglas jurídicas»— es una «condición necesaria» de todo ideal de justicia material (84). Ello permite a LAPORTA ubicarse más o menos cómodamente en los marcos del iuspositivismo convencionalista posthartiano y al mismo tiempo distanciarse de las que considera apelaciones ingenuas y acríticas a la «justicia material» o «sustantiva» peligrosamente presentes en su opinión en las visiones post-positivistas del Derecho: «aquí, a diferencia quizá que en el pensamiento de DwORKIN, no se concibe justicia sustantiva ni material alguna sin la previa justicia formal que emana del imperio de la ley» (ibid.). Así cobran sentido aseveraciones «formalistas» tales como que las reglas son «límites a la decisión basada en la justificación subyacente» (144) o que el ideal regulativo del imperio de la ley «fuerza a los procesos de interpretación y aplicación del Derecho a ser formalistas, puesto que la idea de que sean las reglas las que gobiernen la decisión tiene que suponer [...] un razonable grado de objetividad y ello le acerca al literalismo», de manera que el imperio de la ley «sería también una justificación del formalismo» (191). Este formalismo no sería en principio muy distinto del Formal Style protopositivista criticado clásicamente por LLEWELLYN (1960: 37) por resultar favorecedor de ciertas desviaciones y excesos aún muy extendidos en la cultura jurídica tales como el logicismo y la función meramente declarativa de la jurisprudencia (el razonamiento jurídico es una inferencia de naturaleza puramente formal-deductiva y los jueces no crean nuevo Derecho), la reducción del «verdadero Derecho» a la generalidad y abstracción de las reglas escritas (primacía del legislador y del law in books), el literalismo (la interpretación se reduce a la averiguación de un significado o voluntad objetiva y preexistentemente contenidos en el texto jurídico), el recelo hacia las directrices, principios y otros estándares normativos (visión anticonsecuencialista y antiinstrumentalista del Derecho) y lo mismo hacia los valores (neutralidad político-moral del Derecho).

En la medida, en cambio, en que LAPORTA integra en su libro la tesis anterior sobre la centralidad de las reglas dentro de una visión más compleja y articulada del Derecho de carácter ético-político, tiende a aproximarse a posiciones superadoras del positivismo jurídico. Ahora entiende el Derecho como una institución social realizadora de valores prácticos que lo trascienden y que justifican su propia existencia y operatividad, valores que estarían justamente presentes en la propia formalidad de sus reglas. Específicamente, la existencia institucionalizada del Derecho en la precisa forma de un sistema de reglas es, según LAPORTA, una condición necesaria del valor de la autonomía personal: tal es la tesis de su libro. Una tesis de filosofía moral, pero que engloba al Derecho. La teoría del imperio de la ley basado en la «concepción de reglas» se declara explícitamente como un capítulo («pero solo un capítulo») de «una teoría completa de la Justicia» (83). De manera que «el imperio de la ley ha de ser entendido como un ingrediente de la idea de Justicia, es decir, como uno de los ideales ético-políticos que nos dicen cómo «debe ser»el Derecho positivo» (84).

Este segundo iter argumental viene, en efecto, a distanciar decisivamente el planteamiento de LAPORTA de los marcos doctrinales del iuspositivismo. Lo distancia, desde luego, del legalismo protopositivista: que la justicia formal de reglas no sea una 
condición suficiente de la justicia material excluye cualquier formalismo ingenuo que pretenda apoyarse en la tesis de la completud y determinación del Derecho, en el sentido de que sus reglas contengan ex ante respuestas para toda posible cuestión (en la misma dirección de la tesis hartiana de la textura abierta). Pero también lo distancia de la teorización de las reglas propia de la corriente central del positivismo jurídico contemporáneo (en sus dos versiones, «excluyente» e «incluyente»), para situarlo en la tierra media de un iuspositivismo «ético» o «normativo», que no es sino aquel tipo de positivismo jurídico que comienza a reconocer autocríticamente que necesita dejar de ser positivista para adelantar un paso más allá. Pues la reclamada centralidad de la justicia formal de las reglas ya no se fundamenta, en LAPORTA, sobre sí misma (sobre valores ellos mismos formales, como la seguridad jurídica, la igualdad formal o los principios institucionales que gobiernan el funcionamiento del aparato de la legalidad), ni tampoco sobre valores meramente atribuidos en términos descriptivos, sino sobre valores sustantivos extrajurídicos asumidos como últimos: valores éticos de carácter final, vinculados a la idea misma de persona. $\mathrm{Y}$ es entonces cuando el autoproclamado «formalismo» de LAPORTA se vuelve de inmediato sui generis, ambiguo, sutil y equilibrado, difícilmente encajable ya en acepción alguna convencional del término y cuyas implicaciones son, por el contrario, claramente «antiformalistas». $\mathrm{O}$, al menos, más antiformalistas de lo que tal vez el autor desearía, una vez que ha introducido (como una suerte de «caballo de Troya») los valores morales vinculados a la idea de autonomía - y en definitiva a los derechos humanos - como fundamentos de su teoría del Derecho. En efecto, la tesis de la formalidad necesaria de las reglas se ve a partir de ahora fuertemente condicionada y matizada por la perspectiva de la actuación material de esos valores como razones subyacentes de las reglas que tornan a estas dispositivos formales instrumentales y no fines en sí mismos. Estos valores serían «un conjunto de derechos morales que exigen del sistema jurídico un reconocimiento y protección pleno e igual para todos los miembros de la comunidad como agentes morales» (162). LAPORTA está repitiendo aquí lo que ya nos había dicho al hablar de la normatividad de los derechos humanos: que si estos son «fundamentales» es porque están anclados en ciertos contenidos valiosos o bienes que existen antes de su reconocimiento formal y exigen este, que su forma normativa o deóntica existe solo porque es el vehículo necesario para hacerlos valer generalmente (LAPORTA, 1987: 27 y ss.). Lo mismo sucede ahora con el valor de la autonomía personal, puesto que no se trata de que la configuración del Derecho como sistema formal de reglas garantice la autonomía de las personas, de que la autonomía sea posible porque existan las reglas, sino justamente al revés: es el valor de la autonomía moral (que condensa junto con la igualdad y la libertad las aspiraciones básicas de la dignidad como base moral de todos los derechos humanos, proyectados a lo largo de diferentes frentes tanto éticos como políticos) el que suministra la razón de ser de las reglas jurídicas y fundamenta su racionalidad práctica. Esto convierte al ideal del imperio de la ley en un ideal moral, sin dejar de ser jurídico-formal. En otras palabras: su formalización jurídica se revela entonces necesariamente unida a - y no disociada de - un ideal metodológico de corrección argumentativa sustantiva de las decisiones jurídicas en términos axiológicos en cuanto que aquellos valores y derechos han de prevalecer en la práctica a través de la aplicación de las reglas del Derecho como condición de su validez. Y esto es lo que excluye por principio cualquier género de «formalismo jurídico», al que cabe definir precisamente 
(en cuanto formalismo «negativo» o «desviado») por la operación consistente en desvincular entre sí reglas formales y valores materiales (o presentar el nexo entre ambos en términos contingentes). Pero esta prevalencia de la dimensión justificativa o valorativa resulta plenamente convergente, en modo alguno incompatible, con lo que las teorías post-positivistas del Derecho actuales (apelando a la dualidad reglas-principios o subsunción-ponderación) vienen a defender.

De ahí que en los capítulos finales de El imperio de la ley sea visible cómo el inicial énfasis en los valores formales vinculados a la dimensión autoritativa de las leyes-reglas (generalidad, abstracción, seguridad jurídica) se vea considerablemente rebajado e incluso acabe por invertirse el contraste de partida entre la infraestructura formal de reglas del Derecho y su justificación en términos de derechos y valores de carácter sustantivo. A medida que se incorpora la perspectiva del método jurídico, la prioridad de la dimensión axiológica o material vuelve necesario incorporar también la perspectiva de la racionalidad del juez o aplicador - eclipsada hasta ahora, como sucedía en el formalismo legalista clásico-y restablecer su continuidad justificativa material —no solo autoritativa-formal - con el legislador. La centralidad de los textos legales (Cap. VIII) ya no puede legitimar la producción de decisiones valorativamente injustificables, sino que «los enunciados interpretativos son informes en discurso indirecto de aquello que dijo el legislador y han de tener un fundamento racional» que viene suministrado por «la apelación a un principio de universalizabilidad» (189). Las zonas «ciegas» de la discreción y creación judicial y del Derecho implícito (Cap. IX), zonas en las que el imperio de la ley aparentemente entra en suspenso, quedan vinculadas a pautas de coherencia, derrotabilidad y universalidad, en donde la aplicación de las reglas supone la interpretación retrospectiva y constructiva a cargo del juez consistente en remitir al «propósito del legislador», de forma que «la propuesta de reglas coherentes con el sistema que coadyuven a la satisfacción de un propósito claramente establecido por el legislador no es un supuesto de activismo creador de Derecho» (206). Las propias relaciones entre ley y Constitución (Cap. X) se reconducen a la idea de que «el constitucionalismo no es sino una continuación de la idea de imperio de la ley llevada hasta la constitución misma» (221). Tanto los principios constitucionales como los mecanismos institucionales que los articulan y protegen —es decir, la forma de la Constitución y la justicia constitucional — responden a una justificación material que va más allá de ellos: «y esa justificación solo la pueden dar los "principios" entendidos como razones éticas y políticas $(233) »$.

Decía al principio que esta tensión entre formalismo y antiformalismo queda abierta e irresuelta y que los propios textos de LAPORTA no permiten dirimirla precisamente porque se mantienen ambiguamente en el umbral mismo entre una posición positivista y una posición post-positivista, dando pasos en ambas direcciones y permitiendo espigar pasajes y lecturas tanto en un sentido como en otro. En un trabajo más amplio he desarrollado la hipótesis de que las ideas fundamentales de LAPORTA sobre el imperio de la ley quedan mejor reconstruidas desde una comprensión post-positivista que conciba el Derecho como una práctica argumentativa orientada por valores. Defiendo ahí que la corriente central del iuspositivismo contemporáneo no profundizó suficientemente las importantes críticas avanzadas por HART al primer positivismo $(1957,1994)$ y ello redundó en una teoría de las reglas todavía fuertemente lastrada por elementos 
formalistas. La causa profunda de ello estriba en una de las señas de identidad más características, si no la central, del positivismo jurídico: la pretensión de construir una teoría del Derecho independiente de valoraciones. Ahora bien. las razones de corrección o de carácter axiológico son aquellas que proporcionan los contenidos que operan como justificación última de cualesquiera fines y propósitos a los que una regla pueda apuntar, pues los elementos finalistas que integran el rationale de toda regla están siempre seleccionados desde alguna perspectiva valorativa tomada como justificativamente relevante o última. La desviación o «degeneración» metódica en que incurre lo que llamamos «formalismo jurídico» deriva de sobredimensionar las distintas vertientes de la formalidad de las reglas jurídicas (la «formalidad del contenido», «directiva», «interpretativa» y «autoritativa»; ATIYAH-SUMMERS, 1987: 11 y ss.) pretendiendo poner al margen los elementos materiales valorativos que conforman cada una de ellas. Y esta es justamente la distorsión fundamental que sigue alimentando el positivismo jurídico en su teorización de las reglas como consecuencia de esa pretensión de elaborar una teoría del Derecho libre de valores. El resultado es una visión deformada de la racionalidad de las reglas al reducirla a términos exclusivamente lógico-subsuntivos (generalizaciones constreñidas al esquema de la inferencia formal modus ponens) o técnico-instrumentales (dispositivos decisorios no deliberativos de carácter «perentorio» o contentindependent). En cambio, lo que realmente distingue a una concepción antiformalista del Derecho es colocar su dimensión justificativa —esto es, la dimensión de valor- en una posición de preponderancia. Y precisamente en esta dirección camina la tesis de LAPORTA sobre la fundamentación moral del imperio de la ley en el ideal de autonomía.

En efecto, las razones últimas que justifican a juicio de LAPORTA la forma de ley y en la que basa su propuesta de reformalización del Derecho no son ellas mismas de naturaleza solo formal (autoritativas o procedimentales) sino materiales o de justicia. La forma de ley no es, nos dice, una cuestión «meramente "formal"》 o circunscrita al ámbito de justificación de las normas de competencia y procedimiento, sino «una suerte de ley material que ha de cumplir con las exigencias y razones que hemos dado como necesarias para satisfacer el principio de legalidad, que no es un puro formalismo sino un haz de importantes demandas de carácter ético» (167). Estas demandas tienen que ver con la estructuración del orden social en su conjunto, con «la distribución correcta de los beneficios y las cargas de la cooperación social» (162), con exigencias político-morales que confieren al Derecho «una dimensión de justicia que no puede ser conseguida mediante la utilización de fuentes o normas alternativas» (161). No basta, pues, para fundamentar la formalidad de las reglas (la legalidad), con entender los ideales del imperio de la ley meramente como el conjunto de valores conexos con su generalidad y abstracción (la «moralidad interna del Derecho» de FULLER). Esos valores formales o procedimentales (las «razones para tener reglas» que justificarían globalmente la práctica de actuar sobre la base exclusiva de razones formales) son precisamente valores - y son precisamente esos valores - en la medida en que traducen a su vez determinados valores sustantivos de carácter último. Estos, con la autonomía a la cabeza, imponen así una concepción no formalista del Derecho. Solo se honra la autonomía si se respetan las exigencias de racionalidad práctica derivadas del sometimiento de la acción humana a un régimen de reglas en el que no impere la formalidad (lógica, directiva, autoritativa) de estas sino en cuanto cualificada desde su justificabilidad a la luz de valores materiales. Los parámetros racionales que sustentan la au- 
tonomía en términos puramente formales de «seguridad jurídica» (aseguramiento de ciertas expectativas de conducta estables y ciertas) serían fundamentalmente de orden lógico (claridad, generalidad y consistencia de las leyes), autoritativo (promulgación y publicidad) e instrumental (estabilidad, irretroactividad, regularidad en la aplicación de la ley). Pero estos valores formales asociados a la igualdad y regularidad formal que conforman cualquier práctica decisoria jurídica son siempre utilitarios respecto de valores e ideales sustantivos externos a ellos imputados a una cierta concepción político-moral de la justicia. Ello implica que las razones sustantivas de corrección que se toman en cuenta en el diseño de una regla o procedimiento forman parte interna de estos. Considerarlas «razones formales» entendiendo por tal que no es preciso verificar que se incorporan materialmente a los resultados de su puesta en práctica es precisamente el rasgo característico de un proceder formalista expuesto a la irracionalidad práctica, la injusticia o la arbitrariedad.

\section{REFERENCIAS}

AtiYAh, P. S., y Summers, R. S., 1996: Form and Substance in Anglo-American Law [1987], Oxford: Clarendon Press.

HART, H. L. A., 1957: «Positivism and the Separation of Law and Morals», Harvard Law Review, 71/4: 593-629.

- 1994: The Concept of Law [1961], Oxford: Clarendon Press.

LAPORTA, F., 1987: «El concepto de derechos humanos», Doxa, 4: 23-46.

- 2007: El imperio de la ley. Una visión actual, Madrid: Trotta.

Llewellyn, K., 1960: The Common Law Tradition. Deciding Appeals, Boston: Little, Brown $\&$ Co.

SCHAUER, F., 1991: Playing by the Rules, Oxford: OUP. 